\section{Use of a Soehendra Stent Retriever to Treat a Pancreatic Pseudocyst with EUS-Guided Cystogastrostomy}

The Soehendra stent retriever is reported to be useful for dilating a stenosed pancreatic or biliary duct [1-4]. We have also used it to drain a pancreatic pseudocyst under endoscopic ultrasound (EUS) guidance.

Endoscopic cystogastrostomy with EUS guidance was carried out in three patients (two men, one woman; aged 56, 76 and 45 years, respectively) with pancreatic pseudocysts which developed during chronic pancreatitis. The etiology of the pancreatitis was alcoholic in all three patients, and the cysts were located in the body or tail of the pancreas. The mean diameter of the cysts was $5.9 \mathrm{~cm}$ (range $5.6-6.2 \mathrm{~cm}$ ), and the mean distance between the gastric wall and the cyst wall measured on EUS was $12 \mathrm{~mm}$ (range 9 $14 \mathrm{~mm})$. A 19-gauge puncture needle (Echo-Tip, Wilson-Cook Medical, Inc., Winston-Salem, North Carolina, USA) was successfully inserted into the cysts, but it was not possible to introduce a 7-Fr plastic dilator catheter to dilate the puncture hole in any of the patients. In two patients, an attempt was made to insert a needle-knife electrocautery, but this failed. A Soehendra stent retriever (Wilson-Cook Medical, Inc.) [5] was then used to dilate the puncture hole. The stent retriever was advanced with the aid of the guide wire and torqued clockwise to allow the threads at the end of the device to engage and sufficiently dilate the hole (Figures 1,2). After dilation of the hole, the dilator catheter and the pigtail stent were easily introduced into the cyst in all of the patients. The cysts disappeared, and no recurrences were observed. Minor bleeding was observed in all of the patients. The gastric mucosa became wound round the stent retriever in two patients, but this complication was not serious in either case.

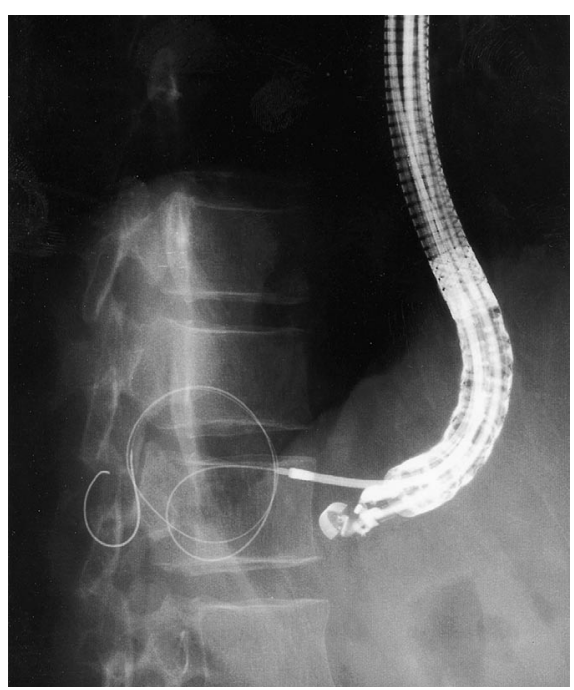

Figure 1 A lateral spot radiograph taken during the procedure. The Soehendra stent retriever is being advanced along the guide wire.

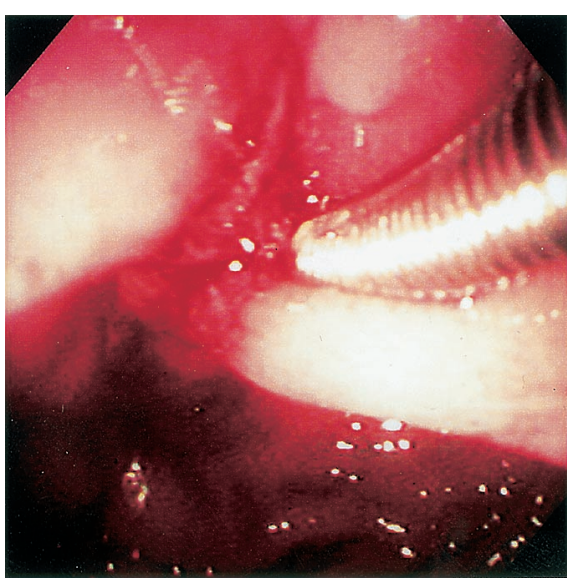

Figure 2 Endoscopic view of the Soehendra stent retriever penetrating through the gastric wall into the cyst.

In endoscopic cystogastrostomy treatment for a pancreatic pseudocyst, use of a stent retriever can be advantageous when the wall is hard and the procedure is difficult with standard dilation techniques.
T. Yamaguchi ${ }^{1}$, T. Ishihara ${ }^{1}$, H. Tadenuma ${ }^{1}$, A. Kobayashi ${ }^{1}$, K. Nakamura ${ }^{1}$, T. Kouzu${ }^{2}$, H. Saisho' ${ }^{1}$

${ }^{1}$ Dept. of Medicine and Clinical Oncology, Graduate School of Medicine, Chiba University, Chiba, Japan

2 Dept. of Endoscopic Diagnosis and Therapeutics, Graduate School of Medicine, Chiba University, Chiba, Japan.

References

${ }^{1}$ Faigel DO, Ginsberg GG, Kochman ML. Innovative use of the Soehendra stent retriever for biliary stricture recanalization. Gastrointest Endosc 1996; 44: 635

2 Vida F, Ball TJ, Kozarek RA, Raltz SL. New application for the Soehendra stent retriever. Gastrointest Endosc 1998; 47: $109-110$

${ }^{3}$ Ziebert JJ, DiSario JA. Dilation of refractory pancreatic duct strictures: the turn of the screw. Gastrointest Endosc 1999; 49: 632-635

${ }^{4}$ Brand B, Thonke S, Obytz KFet al. Stent retriever for dilation of pancreatic and bile duct strictures. Endoscopy 1999; 31: $142-145$

${ }^{5}$ Soehendra N, Maydeo A, Eckmann Bet al. A new technique for replacing an obstructed biliary endoprosthesis. Endoscopy $1990 ; 22$ : $271-272$

\section{Corresponding Author}

\section{T. Yamaguchi, M.D.}

Dept. of Medicine and Clinical Oncology Graduate School of Medicine,

Chiba University

1-8-1 Inohana, Chuo-ku

Chiba 260-8670

Japan

Fax: $\quad$ + 81-043-226-2088

E-mail: yamaguch-cib@umin.ac.jp 